\title{
Editorial
}

\section{Unos resultados electorales desafiantes}

Las elecciones del 12 de marzo cumplieron un doble propósito. El primero y formal consistió en otorgar un nuevo mandato de tres años para los gobiernos locales y los diputados de la Asamblea Legislativa. El segundo, no buscado de manera expresa, consiste en haber puesto en evidencia el agotamiento del sistema electoral como medio para promover y consolidar la democratización, y la necesidad urgente de reformarlo. Por lo primero se dio cumplimiento a uno de los requirimientos fundamentales del régimen democrático, mientras que el segundo es una advertencia más sobre la necesidad de impulsar cambios sociales radicales que garanticen el avance y la consolidación de la democratización de El Salvador.

Ciertamente, las elecciones del 12 de marzo y el reconocimiento de sus resultados por parte de todos los actores son acontecimientos importantes dentro del desarrollo democrático salvadoreño. Pero esta apreciación está referida sólo al primer propósito de las elecciones y no debe llevar a perder de vista el segundo, que apunta a la crisis del sistema político en general y a la del sistema electoral en particular. Y no puede ser de otra manera, dadas las circunstancias actuales. Las elecciones recién pasadas representan un desafio para el sistema político salvadoreńo al mostrar que la democratización no avanza de manera mecánica, jalonada por elecciones periódicas, $y$ al advertir que éstas pueden estar a punto de convertirse en una mera formalidad. Esto significaría que el proceso de democratización corre el riesgo de estancarse - al igual que la economía nacional- y, lo que es más grave, que su reversión es una posibilidad real y no remota.

Plantear la problemática dejada por las elecciones del 12 de marzo en términos de tres desafíos —el de la realidad, el del abstencionismo y el del buen gobierno- tiene la ventaja de no rehuir las dificultades existentes al mismo tiempo que invita a cargar con ellas para encargarse de ellas y así 
evitar el riesgo del estancamiento, el cual podría degenerar en la reversión de lo ganado con la transición.

\section{El desafío de la realidad}

Los partidos políticos están tan enajenados del acontecer de la realidad nacional que ya no marcan su ritmo. Desde hace algún tiempo, los políticos viven enclaustrados en un mundo construido a su medida, pero, por eso mismo, ajeno al proceso de la realidad nacional o, al menos, al acontecer de la vida de la mayoría de la población salvadoreña. Son pocas y contadas las ocasiones en las cuales los políticos se encuentran forzadamente con los pies en la tierra. Una de esas raras ocasiones son las elecciones.

Aunque las campañas electorales de los diversos partidos más parecían presidenciales que locales y regionales, ninguno de los graves problemas que agobia a El Salvador fue tratado con seriedad. Este desentendimiento de la realidad concreta es más chocante porque mientras se desarrollaba la campaña, el Seguro Social se encontraba en huelga y la crisis del sistema de salud ocupaba el primer lugar en la agenda pública. Con todo, un avance de estas elecciones fue que los partidos se sintieron obligados a presentar plataformas legislativas e incluso municipales - aunque sólo las de ARENA y el FMLN pueden ser consideradas como tales, en sentido estricto. Sin embargo, todas las plataformas se caracterizan por la generalidad. Ninguna de ellas se atreve a proponer las medidas específicas a través de las cuales se concretizarían los principios enunciados, ni muchos menos a estimar los costos financieros de las mismas y a establecer los plazos de cumplimiento. Así, mientras el FMLN prometía reformar la ley de armas de fuego sin señalar los artículos en cuestión ni el sentido de las modificaciones que se propone introducir, o cómo se podría manejar una disminución de tres puntos porcentuales en el impuesto al valor agregado; ARENA hablaba de un nuevo endurecimiento de la legislación para combatir la delincuencia sin especificar qué leyes reformaría, ni el sentido de dicha reforma.

Esta falta de concreción en las propuestas puede deberse a cierto temor a adquirir compromisos concretos, los cuales después podrían ser exigidos, al desconocimiento de las medidas que deben ser adoptadas para concretar los ofrecimientos electorales, o a razones propagandísticas o a una combinación de las tres. Los partidos políticos están lejos de cumplir su cometido en cuanto a informar a la población sobre sus planes de gobierno. La ciudadanla se conforma cada vez menos con generalidades y con votar de acuerdo a las directrices emanadas de la dirección del partido.

En todas las plataformas predomina la visión legalista de la práctica política. Los políticos, por lo general, tienden a seguir pensando que legislar es gobernar. De ahí el énfasis desmesurado en la proposición de leyes nuevas o en la reforma de las actuales. Los partidos políticos parecen desconocer, por un 


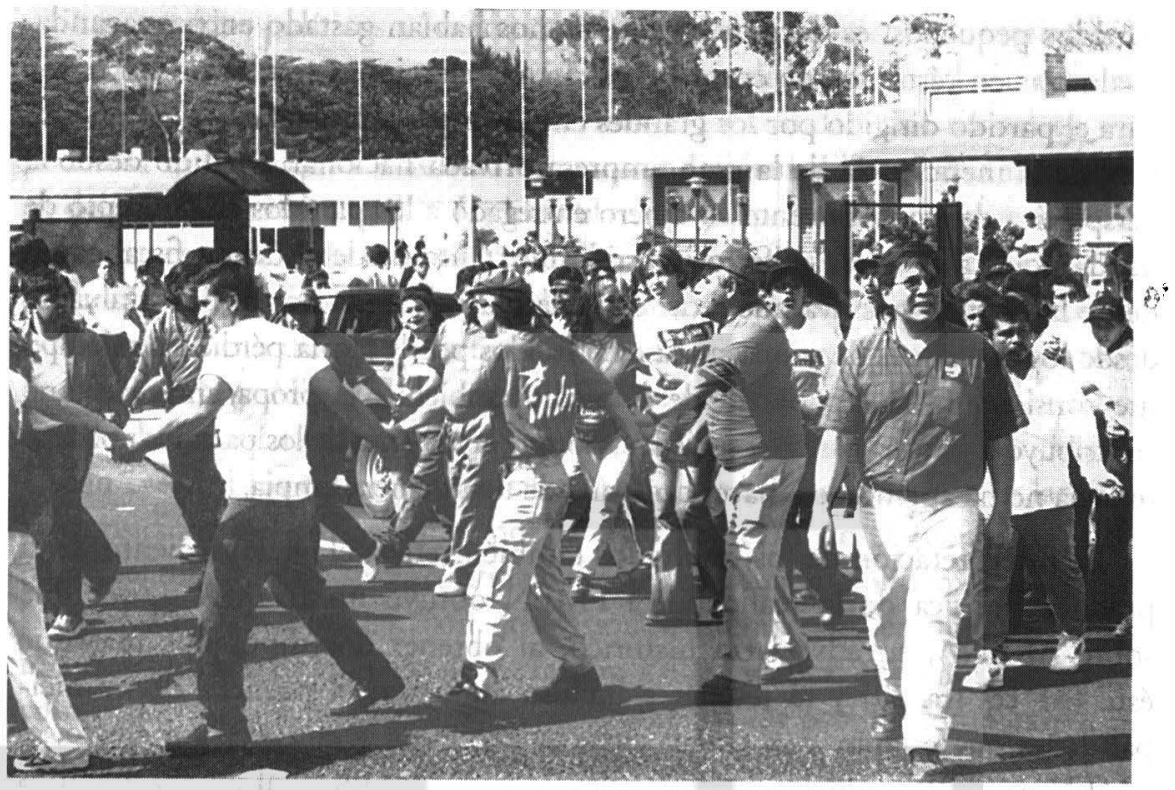

lado, que la mayor parte de la población —el 59 por ciento, según las encuestas del Instituto Universitario de Opinión Pública (IUDOP)— no está interesada en la legislación, porque está convencida que ésta muy pocas veces o nunca la favorece, y, por el otro, que los problemas de El Salvador no se originan en la falta de leyes, sino en su incumplimiento. Hubiera sido más modesto, pero también mucho más útil y realista, que los partidos políticos se comprometieran a revisar la consistencia del cuerpo legal existente y a esmerarse para que las instituciones responsables velen por su aplicación estricta, sin excepción ninguna. Lo primero es una tarea impostergable para eliminar las contradicciones existentes entre las diferentes leyes, para llenar vaclos legales y para dotar a un sinnúmero de ellas de sus reglamentos respectivos. La situación jurídica actual es fruto de la ligereza y la ignorancia del legislador. Lo segundo es básico para el fortalecimiento institucional, el cual es socavado de manera continua por el privilegio y la corrupción. Plantear la campaña legislativa en torno a la legislación fue un error, porque no sólo muestra el desconocimiento del sentir popular por parte de los políticos, sino porque también dejó de lado una de las carencias más notables de la actividad legislativa de los últimos años.

No obstante que, al igual que en elecciones recién pasadas, cerca del 80 por ciento de quienes concurrieron a las urnas había decidido su voto antes que la campaña electoral diera comienzo, los partidos políticos, y en particular ARENA, gastaron decenas de millones de colones en propaganda de toda clase. Sólo una proporción muy pequeña de quienes concurrieron a las urnas (el 11 por ciento, según el IUDOP) decidió su voto durante la campaña electoral y quienes lo decidieron el mismo 12 de marzo, favorecieron a los 
partidos pequeños, es decir, a los que menos hablan gastado en propaganda. Evaluadas en términos de costo-beneficio, las elecciones resultaron un fiasco para el partido dirigido por los grandes empresarios salvadorefios. Una muestra más de la ineficiencia de la gran empresa privada nacional. Medido desde la perspectiva del contribuyente, el dinero entregado a los partidos en concepto de deuda polírica es un despilfarro injustificable, tanto desde el déficit fiscal como desde la carga impositiva que recae sobre la mayoría de la población. Evaluadas desde los dos meses de propaganda establecidos por la ley, la pérdida de tiempo fue considerable. Evaluadas desde el medio ambiente, la propaganda electoral contribuyó a generar basura y suciedad, porque la mayorfa de los partidos políticos todavia no ha aprendido a hacer campaña de una manera limpia.

La interpretación de los resultados también refleja el enajenamiento de la práctica política de la realidad. El FMLN obtuvo un triunfo indiscutible sobre ARENA, su adversario histórico, al obtener dos diputados más que éste (31 contra 29) y al retener e incluso aumentar el número de municipalidades que estarán a su cargo, entre el año 2000 y el 2003. En efecto, el FMLN ganó 30 municipios adicionales, lo cual hace un total de 78; mientras que ARENA perdió 36, quedándole 124. Es cierto que ARENA obtuvo un diputado más que en las elecciones de 1997, pero su meta fueron 39 diputados y 206 alcaldías - al menos según las expectativas del presidente del partido. Es así como la mayor parte de la población del país será gobernada localmente por el FMLN, en los próximos tres años.

El FMLN ha interpretado estos resultados, indiscutiblemente favorables, como un apoyo mayoritario de la población. En realidad, lo que se dio fue un virtual empate a nivel nacional entre el FMLN y ARENA —superando este último a aquél en casi diez mil votos. Este empate se ha producido no por un crecimiento pujante del FMLN, sino por la pérdida constante de votos de ARENA, un fenómeno detectado meses antes de las elecciones por el IUDOP. El caudal de votos a nivel nacional a favor del FMLN ha crecido de manera gradual desde 1994, cuando participó por primera vez en una elección. Pero su crecimiento fue más acelerado entre 1994 y 1997 que entre 1997 y 2000 . ARENA, en cambio, experimentó un descenso considerable en 1997, del cual no ha podido recuperarse aún, acercándose así al FMLN. De momento, por lo tanto, se han enfrentado el voto duro del uno contra el voto duro del otro. El FMLN puede sentirse satisfecho por ser el beneficiario principal del descalabro electoral de ARENA, pero no puede dar como un hecho que es aceptado por la mayoría de la población —sólo votó por él el 11.68 por ciento del total de la población en edad de votar. La consolidación y el avance de sus posiciones depende de un crecimiento más acelerado y del estancamiento de ARENA. La euforia del triunfo no debiera hacer que los partidos políticos perdieran de vista las realidades sociales de El Salvador. 
Los partidos políticos salvadoreños se caracterizan por su voluntarismo, es decir, tienden a imponer su voluntad sobre la realidad nacional. Su esfuerzo ha resultado tan sobrehumano como inútil. La realidad por ser tal es más poderosa que cualquier voluntad humana individual. El caso más notable es el del Centro Democrático Unido, el cual ha pretendido, sin éxito aún, colocarse en medio de un espectro político que considera polarizado por dos extremas. La dirigencia de esta coalición sostiene la necesidad de un centro que contribuya a disminuir la tensión creada por los extremos, representados por el FMLN y ARENA. El centro es una propuesta interesante; la cuestión es su viabilidad. La polarización no es tan intensa como el Centro Democrático Unido cree, ni los extremos son tales. Aquélla ha ido cediendo a lo largo de la transición, en gran medida por la incorporación de la fuente de dicha polarización, la cual se encontraba fuera del sistema político. Por el otro lado, existen dos bloques, con dos visiones diferentes $y$, en algunos temas, incluso contradictorias, pero no extremos. En la práctica, al menos, no actúan como tales. La mayoría de la población tampoco los percibe como extremos. Al contrario, tiende a confundirlos - cosa que molesta mucho al FMLN. La confusión es reforzada porque las conveniencias mutuas hacen que los dos bloques tiendan a actuar de consuno.

Contrario a lo que los partidos políticos sostienen, al menos en sus discursos públicos, el gran ganador de las elecciones recién pasadas - si es que se puede hablar en estos términos - es la abstención —alrededor del 67 por ciento a nivel nacional, aunque desciende un poco en el municipio de San Salvador.

Un centro que se intente definir a partir de la existencia de dos extremas no es, por lo tanto, realista. Tampoco lo es desde la perspectiva electoral, cuando la polarización suele ser más intensa entre los dos bloques que dominan la actividad política; pero, en este caso, la mayoría de la población se mantiene alejada de las urnas. El centro podría tener posibilidades si fuera independiente de las líneas políticas partidarias tradicionales y si tiene habilidad para acercar sectores, que actúan en campos contrarios o ajenos.

El alejamiento de la práctica política de la realidad no es cosa nueva. La Asamblea Legislativa es una de la instituciones estatales cuyas actividades son desconocidas por la mayoría de la población y una de las peor evaluadas por la opinión pública. En los últimos tres años, la Asamblea Legislativa no ha podido elevar el poco aprecio que la población tiene de ella. El resultado electoral, en particular el desinterés de la población, está determinado, en gran medida, por lo que ha sido la legislatura saliente y no por la propaganda electoral. Sin embargo, los partidos políticos no parecen haberse percatado 
de este hecho. El caso del municipio de San Salvador es paradigmático, porque ARENA, pese a su millonaria inversión, no pudo acortar la brecha que, desde el comienzo de la campana, separaba a su candidato de su contrincante principal.

Es evidente, excepto para los partidos políticos, que las candidaturas no se improvisan. La maquinaria electoral de los partidos es indispensable para sacar adelante una candidatura, pero no deja de ser un mero instrumento, que, en cuanto tal, no siempre puede reemplazar la ausencia de una gestión pública que beneficie de manera directa a la población, ni la credibilidad ni la confianza que el candidato pueda generar en ésta. Ahora bien, a veces la maquinaria funciona. Es el caso del FMLN, en Soyapango y Santa Ana, donde sus militantes votaron de manera disciplinada por los candidatos impuestos por el partido, auh cuando no eran los más populares.

Uno de los errores más graves cometido por los partidos políticos salvadoreños es haberse despreocupado del bienestar de la población para ocuparse casi de manera exclusiva por sus propias conveniencias. Por lo tanto, es absurdo esperar que la población vote por uno de ellos, arrastrada por su propaganda. La propaganda no impacta en los consumidores potenciales sin un mínimo de calidad constatable en el producto que ofrece. En este sentido, es mérito de la población salvadoreña no haber sido sujeto pasivo de una propaganda que buscaba llevarla a las urnas cuando de ello no se derivaba ningún beneficio directo $y$ visible para ella.

Así, pues, el primer desafio que enfrentan los políticos salvadoreños es la realidad de la población a la cual dicen representar y a la cual aseguran querer servir. La mayoría de esa población no se siente representada por ellos y es obvio que tampoco quiere ser servida por ellos. Los partidos políticos debieran hacer un alto para identificar aquellos intereses grupales e incluso personales que se interponen entre ellos y los de la población, supeditando aquéllos a éstos, para desterrarlos de su práctica habitual. Los intereses más contrarios al bien general son los del poder - bien sea político, financiero, social, etc. - y las ambiciones personales. Los partidos deben escoger a quién quieren servir, al bien general, entendiendo por tal el bienestar de la mayoría de la población salvadoreña, o al poder. En la medida en que sirvan al poder, la población los rechaza. La tarea no es fácil, porque la tentación del poder es demasiado fuerte y porque el objetivo fundamental de los partidos políricos es el poder. El desafío que tienen planteado, entonces, es cómo conciliar el poder con el servicio a la mayoría de la población.

\section{El desafio de la abstención}

Contrario a lo que los partidos políticos sostienen, al menos en sus discursos públicos, el gran ganador de las elecciones recién pasadas - si es que se puede hahlar en estos términos- es la abstención -alrededor del 67 
por ciento a nivel nacional, aunque desciende un poco en el municipio de San Salvador. Si, por otro lado, sólo se toman en cuenta los votos válidos, resulta que los diputados de la legislatura 2000-2003 han sido elegidos por aproximadamente un tercio de la población en edad de votar (33.17 por ciento), lo cual cuestiona su representatividad, aunque no su legitimidad. De esta manera, la trascendencia de los resultados electorales que dan al FMLN una ventaja importante sobre ARENA, su adversario histórico, es relativa. $\mathrm{Ni}$ la ventaja del uno, ni la desventaja del otro son tan absolutas, al menos en términos de representatividad. Ninguno de los dos partidos grandes tiene un cheque en blanco para decidir según sus conveniencias en los próximos tres años, sino que ambos tienen planteado el desafío de hacer un buen gobierno legislativo y local para ampliar su aceptación por parte de la población y aumentar asi su potencial electoral. Este resultado tampoco puede ser interpretado como una decisión buscada de una manera consciente por un electorado que quería castigar a uno y otorgar una ligera ventaja al otro. La respuesta es más simple, la abstención, que tiene su explicación propia, favoreció, en esta ocasión, al FMLN.

Aun cuando el orden político establecido llamó con insistencia a votar y aun cuando los partidos politicos necesitaban del voto de la población para satisfacer sus expectativas electorales, el cuerpo electoral no concurrió a las urnas. Una porción considerable de población en edad de votar ni siquiera se ha documentado. Los repetidos llamados, incluso el mismo día de las elecciones, invitando a votar, no tuvieron eco. La ciudadanía no concurrió a las urnas, porque no se encontraba motivada —excepto en el municipio de San Salvador, donde la motivación era un poco mayor-, porque mantiene una desconfianza fundamental ante el proceso electoral mismo $y$, sobre todo, porque considera que su voto no contribuye a cambiar la situación del pals. Esta valoración es especialmente critica, porque la inmensa mayor parte de la población quiere cambios.

Estas apreciaciones están sustentadas en el resultado de la encuesta de salida del IUDOP. La mayoría de quienes votaron lo hizo por considerarlo un "deber" y sólo una minoría (5.2 por ciento) votó para apoyar a su partido. Aun así, un sector importante de quienes votaron, lo hizo porque pensó que su acción contribuiría a cambiar o a mejorar el estado de cosas en el pais. Casi la mitad de quienes

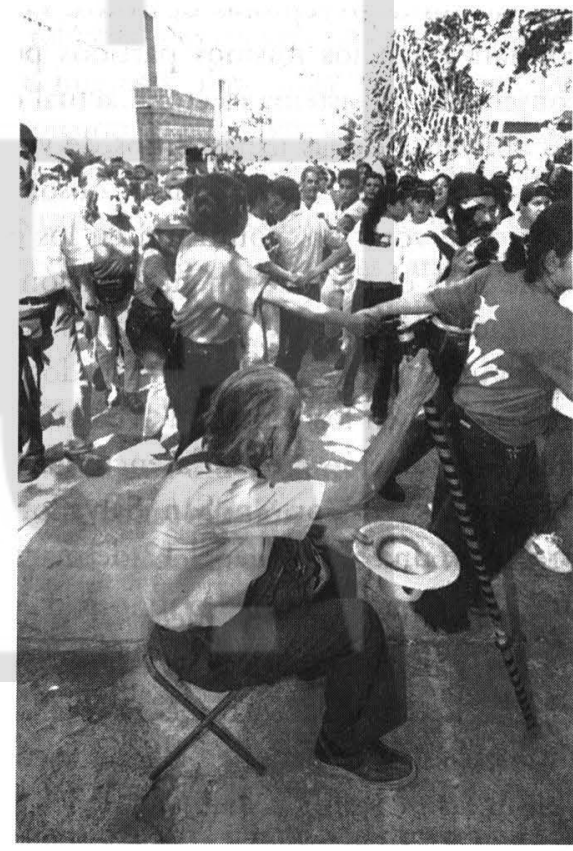


votaron asegura tener mucha confianza y casi un tercio dice tener algo de confianza en el sistema electoral. Este segmento del cuerpo electoral es el que más confianza muestra en el sistema, pero es superado por mucho por el que piensa exactamente lo contrario. Existe una relación directa entre participación, interés y confianza en el sistema electoral.

El desinterés y la desconfianza han sido cultivados de manera sistemática por los mismos partidos políticos, los cuales pretendían, en vano, conquistar en dos meses lo que no quisieron o no pudieron hacer en tres años de gestión, en el gobierno local o en la Asamblea Legislativa. En esos dos meses proyectaron una imagen equívoca de la Asamblea Legislativa y del interés de los partidos políticos por servir a la población, mientras la atiborraban de toda clase de promesas. El resultado electoral comprueba, una vez más, que la improvisación de candidaturas conlleva un alto riesgo. La maquinaria electoral de los partidos políticos grandes puede impulsar una candidatura improvisada, pero incluso para aquellas que son más poderosas, la improvisación se puede convertir en un obstáculo insalvable, tal como lo comprueba el caso de ARENA, en el municipio de San Salvador.

Por extraño que pueda parecer a estas alturas de la postguerra, la mayor parte de la población abriga dudas sobre la limpieza del proceso electoral. Esas dudas se remontan a las elecciones de la década de los ochenta y a una desconfianza casi innata ante la actividad política. Sin embargo, esas dudas se han visto confirmadas en las elecciones de los noventa por una serie de vicios que no sólo no han podido ser erradicados, sino que se han venido generalizando hasta llegar al punto de haber indicios serios de fraude en algunas juntas receptoras de votos. Los responsables principales de esta desconfianza son los mismos partidos políticos, porque son ellos los que han conservado un sistema electoral actual el cual, en lugar de atraer a los votantes, los ahuyenta de las urnas: sitios de votación alejados del lugar de residencia, transporte insuficiente, padrón obsoleto, falta de información sobre y en el centro de votación, confusión en los electores al no coincidir el nombre del carné con el del padrón, usurpación del derecho a votar, votación desorganizada, incapacidad y prepotencia de algunas juntas receptoras de votos y de algunos vigilantes de los partidos, confrontación entre los militantes de los partidos en los centros de votación, compra de votos y propaganda en los sitios de votación. Según la encuesta de salida del IUDOP, más de un tercio de quienes votaron en San Salvador encontró al menos una dificultad o presenció una anomalía, el 12 de marzo.

El Tribunal Supremo Electoral, integrado en su mayoría por representantes de los parridos políticos y cuyos cargos se reparten de acuerdo a cuocas establecidas por la costumbre, es el árbitro de esta estructura obsoleta. Su obsolescencia se debe, en buena medida, a su debilidad e impotencia para resistir las presiones y chantajes de los partidos políticos. El máximo organismo 
electoral no es independiente de ellos, aunque debiera serlo, según la ley. Pero su contradicción más grave es que no aplica la ley electoral de acuerdo al interés general, sino según el interés de aquellos partidos que lo controlan, es decir, ARENA y sus aliados. Esto no significa, sin embargo, que descuide los intereses del FMLN y de los otros partidos pequeños, pero siempre y cuando sus decisiones no perjudiquen en demasía a ARENA y sus aliados. De hecho, el Tribunal Supremo Electoral hace valer su autoridad con mucha dificultad. Al igual que otras instituciones claves del régimen democrático salvadoreño, el Tribunal Supremo electoral ha perdido el control —si es que alguna vez lo tuvo en realidad- del proceso electoral. En las elecciones recién pasadas no pudo obligar a los partidos a cumplir con la norma que rige el desarrollo de la campaña electoral; no pudo organizar las elecciones de una forma tal que los vicios ya conocidos fueran erradicados del todo o disminuidos en una forma significativa; no pudo impedir la propaganda en los sitios de votación y se vio sorprendido por varias denuncias de fraude, presentadas por diversos partidos en contra de ARENA, de tal manera que se apresuró a declarar definitivos los resultados ya obtenidos, sin atreverse a investigar las denuncias presentadas.

Desde la elección de 1994, la reforma del sistema electoral ha sido tópico postelectoral, pero los partidos políticos todavla no la han considerado en serio. Unos por una razón y otros por otra, todos consideran que el sistema actual, aun con sus limitaciones y anomalías, satisface sus expectativas. Por eso es irónico que a la vista de unos resultados que no los favorecen, algunos de ellos se lancen contra el sistema del cual son responsables directos. El gran ausente es el elector, a quien los partidos políticos ni siquiera consideran cuando discuten sobre la introducción de reformas electorales. Las discusiones se centran alrededor de sus conveniencias e intereses, pero muy rara vez en las necesidades y gustos de aquél. Como el voto no es atractivo, ni útil, ni fácil, el elector se mantiene alejado de las urnas, evidenciando todavia más la brecha que separa a los políticos de la sociedad. No es extraño, entonces, que a lo largo de la década de los noventa, la abstención se haya convertido en una de las características de las elecciones salvadoreñas —dos presidenciales (1994 y 1999) y tres do diputados y concejos municipales (1994, 1997 y 2000): 51.4 y 66.8 por ciento, en las dos primeras, y 51.4, 65.7 y 67, en las tres últimas.

Una abstención tan elevada como la de las dos últimas elecciones (1999 y 2000) tiene consecuencias negativas para la consolidación de la democracia, en El Salvador. La abstención cuestiona el alcance del proceso de democratización, iniciado en 1992. Lo menos que podría haberse esperado de éste es una participación mayor de la ciudadanía. Pero ésta aún no está convencida de que votar sea un deber o que éste tenga alguna utilidad. Es así como, en lugar de conservar o aumentar el nivel de votación de comienzos de la transición, éste ha venido descendiendo de manera llamativa. $\mathrm{El}$ proceso de democratización no puede ir en la dirección correcta cuando la mayoría de la 
población se mantiene al margen de una de las prácticas claves del mismo. No deja de ser paradójico que cuando más se enfatiza la participación, menos población concurre a las urnas. Sin embargo, de aquí no se deduce que la población sea apática, porque ésta participa, y muy activamente, cuando comprueba que su acción incide en el curso de los acontecimientos e influye en el curso de su vida y en la de los suyos.

Al igual que otras instituciones claves del régimen democrático salvadoreño, el Tribunal Supremo electoral ha perdido el control -si es que alguna vez lo tuvo en realidad - del proceso electoral.

Este grupo mayoritario que se abstiene, conformado en buena parte por mujeres y jóvenes, no sabría diferenciar entre un partido u otro, entre unos políticos u otros. Para ella, todos son iguales, es decir, le son indiferentes, porque sus decisiones no influirán positivamente en su vida. Aunque el FMLN reacciona molesto al ser colocado de manera indiferenciada entre los partidos políticos y sostiene que él hace la diferencia, es un hecho incontestable que la mayor parte de la población no lo percibe así. En este sentido, no debiera llevarse a engaño, a partir de los resultados obtenidos en las elecciones recién pasadas, acerca del apoyo real con el cual puede contra en la población (11.7 por ciento de la población en edad de votar). Es cierto que ha venido creciendo de manera gradual desde 1994, pero entre 1997 y 2000, su crecimiento no es tan voluminoso como pareciera.

En buena medida, esta actitud de aparía e indiferencia ha sido cultivada y alimentada por el orden politico establecido. Entre 1982 y 1991, dicho orden enfatizó que votar era una necesidad para alcanzar la paz, pero el final de la guerra no llegó por la vía electoral, sino por el diálogo y la negociación de las cúpulas. Desde 1992, el orden político establecido viene prometiendo que el voto es la solución para la inseguridad ciudadana y la pobreza; pero la población constata año con año que su situación familiar no mejora y, en alguno casos, incluso empeora. En suma, las elecciones no proporcionan lo que partidos y candidatos prometen. Al menos no lo ha hecho en dos décadas de una manera inequívoca (cfr. A. Artiga, "La democratización y el proceso electoral de 2000", ECA, 615-616, 2000, p. 105). Entonces, pareciera que las elecciones no serían el instrumento más idóneo para conseguir aquellos cambios que la población salvadoreña más desea.

Si las elecciones constituyen uno de los mecanismos fundamentales con los cuales el régimen democrático cuenta para conseguir el cambio, pero es incapaz de entregar lo prometido, ¿qué alternativa queda pára esa mayoría salvadoreña que desea un cambio radical? 


\section{Desaffo del buen gobierno}

De la respuesta que se dé a la cuestión anterior depende el futuro de $\mathrm{El}$ Salvador. La mayoría de la población reclama cambios radicales y rápidos, y es indudable que El Salvador necesita de esos cambios. Lo nuevo, mucho o poco, que la transición haya podido traer, no es la cuestión ahora; sino que esas novedades no han podido erradicar las causas fundamentales que llevaron a la guerra, en la década de los ochenta. Basta un dato para constatarlo: la población salvadoreña se sigue viendo forzada a emigrar hacia el norte. Uno de cada cuatro adultos quisiera emigrar. El agotamiento del cual da muestras el sistema electoral actual es parte de un agotamiento mayor, que comprende a todo el régimen político. Habría suficientes razones como para afirmar que el ciclo abierto por los acuerdos de paz se habría cerrado ya y uno nuevo se estaría iniciando ahora. La cuestión es en qué dirección se va a mover El Salvador, en los próximos años.

El buen gobierno no es sólo cuestión de buena voluntad, de conveniencia política o ideologla, sino que conlleva una componente irremplazable de saber y ciencia. Además de la disposición a trabajar

por el bien común y para hacer lo políticamente correcto, es indispensable saber gobernar para que el gobierno sea sabio.

La incapacidad de las elecciones para entregar el cambio social prometido, siendo al mismo tiempo el único instrumento que la democracia puede ofrecer para impulsarlo, plantea un dilema, que tiene consecuencias graves para El Salvador. Si no se emprende pronto el camino de la reforma social, gradual y sostenible, pero sistemática y radical, sólo queda la alternativa del malestar social creciente, el cual, muy probablemente, se irá convirtiendo, más temprano qué tarde, en protesta y desorden callejero $y$, eventualmente, en conficto abierto. De hecho, el malestar social es innegable y las primeras protestas organizadas han comenzado a tener lugar. Este es el desafio insoslayable del buen gobierno que los partidos políticos tienen planteado y con ellos, de manera indirecta, la sociedad en su conjunto.

El gobierno local de la mayor parte de la población salvadoreña es una oportunidad única para que el FMLN pueda demostrar la diferencia radical existente entre él y los otros partidos políticos así como para que él mismo profundice en su experiencia del ejercicio del poder. Esa diferencia es bastante clara en la municipalidad de San Salvador; pero, sin duda, puede definirse mejor aqui y en los otros municipios del país. El FMLN tiene en sus manos una oportunidad única para demostrar ante la sociedad salvadoreña qué significa un buen gobierno local, un tema que, por otro lado, es de gran actualidad y en el cual él mismo ha insistido mucho. Si bien los 31 diputados 
del FMLN que formarán parte de la nueva legislatura no tienen la mayoría, sí cuentan con una plataforma con proyección nacional para hacer una verdadera oposición. Esta es otra oportunidad para dar voz a las necesidades y aspiraciones de la mayoría de la población salvadoreña y para luchar por el desarrollo sostenible de El Salvador. Por razones inexplicables, pero que se pueden adivinar, el FMLN todavía no se ha constituido en la oposición que la sociedad salvadoreña necesita. Aún es débil, y no precisamente porque no tenga los votos necesarios para imponer su voluntad en el seno legislativo, sino porque sus razones con demasiada frecuencia no son oportunas y a veces sus acciones tampoco son consistentes.

El buen gobierno no es sólo cuestión de buena voluntad, de conveniencia política o ideologla, sino que conlleva una componente irremplazable de saber y ciencia. Además de la disposición a trabajar por el bien común y para hacer lo políticamente correcto, es indispensable saber gobernar para que el gobierno sea sabio. Y esta es una de las debilidades más grandes del FMLN actual. Las consecuencias del mal gobierno en la localidad, en la legislatura y en el ejecutivo se pueden observar, como en un espejo invertido, en ARENA. El triunfo del FMLN debe más al mal gobierno de ARENA que al entusiasmo popular. El descontento de los simpatizantes de ARENA con su partido y su gobierno así como el rechazo de buena parte de la población hacia las prácticas de este partido es indudable; pero no está claro todavía que el FMLN sea la opción de la mayoría. ARENA puede perder el control del Estado, pero no está decidido aún si esa derrota le será propinada en un futuro cercano por el FMLN.

El FMLN todavía tiene que convencer a una buena parte de la ciudadanía sobre su capacidad para gobernar y sobre la diferencia evidente que haría un gobierno suyo respecto al de los otros partidos. Aquí es dónde la ciencia y el saber son claves para el éxito político. En segundo lugar, para que esa diferencia sea real, y no sólo ideológica o intencional, el FMLN debe cuidarse mucho de las tentaciones inherentes al poder. Para contrarrestarlas, debiera ser el partido donde la ética polírica ocupara un lugar preponderante, tanto como para poder convertirse en un ejemplo indiscutido para los demás partidos. En tercer lugar, el FMLN debe identificarse mucho más con las necesidades de las mayorlas salvadoreñas y asi generar confianza y recuperar su credibilidad. En cuarto lugar, la unidad del FMLN es estratégica para alcanzar estas metas. La existencia de corrientes políticas diferentes en su seno no se opone necesaria e inevitablemente a su unidad, pero esas corrientes deben ser dirigidas con gran lucidez en el análisis y la práctica política. Estos desafíos que el FMLN tiene delante de sí no debieran ser opacados por el resultado del 12 de marzo. Si el partido se dedica con diligencia a enfrentar estos desafios, podría despertar un nuevo impulso con potencial para despertar entusiasmos ahora casi olvidados. Ahora bien, si el partido deja pasar esta oportunidad, en la situación actual de ARENA puede ver por anticipado lo que le aguarda. 
Los cambios que la sociedad y la realidad demandan pasan por el replanteamiento de las relaciones entre la sociedad y el Estado. Más en concreto, la sociedad debe adquirir poder para controlar a los partidos políticos y también a las instituciones estatales.

ARENA también necesita esmerarse mucho para gobernar bien en lo que queda de un mandato presidencial que todavía no cumple su primer año y en la nueva legislatura, en la cual, aunque no tiene mayoría, cuenta, sin embargo, con una cuota de poder determinante. El partido no obruvo los votos que necesitaba para satisfacer sus expectativas porque, a juicio de la población, está gobernando mal. De quienes concurrieron a las urnas el 12 de marzo, sólo aquellos que votaron por ARENA aprueban la gestión del presidente Flores. Más que la propaganda, es el buen gobierno lo que atrae los votos y buen gobierno significa beneficiar y no perjudicar a la mayoría de la población, que ya sobrevive en condiciones bastante precarias. Este es un principio básico de la democracia, pero ARENA parece desconocerlo o haberlo olvidado. Esto se desprende de la desorientación de su campaña electoral que, en lugar de atraer votantes, los ahuyentó. En este sentido, la conducción de la huelga del Seguro Social arrojó un saldo negativo para el partido y su gobierno. Ambos la utilizaron para desgastar al FMLN, sin percatarse que, aunque la mayoría de la población estaba en contra de ella, cargaba sobre el gobierno de Flores la responsabilidad por no buscarle un final razonable. Cuando cayeron en la cuenta de su error, ya era tarde y, además, el director de la Polića Nacional Civil confirmó los peores presagios, al reprimir a los huelguistas sin razón alguna.

El presidente Flores parece haber caído en la cuenta de su mal gobierno y se propone corregirlo con hechos. Pero para que éstos puedan convertirse en buen gobierno es necesario tener un plan y una dirección, cosas de las cuales el gobierno actual parece carecer. Sin embargo, hay que reconocer la rápida reacción del presidente Flores ante el resultado adverso de las elecciones al proponer concertar con vistas a hacer un buen gobierno. La propuesta era importante y necesaria, pero debe ser recibida con cierta reserva, porque al comienzo de su gobierno también ofreció concertar y porque apenas unos pocos días antes descalificó a su rival principal como contrario al sistema, recordando para ello la guerra de los ochenta, supuestamente un hecho ya olvidado. El pasado todavía pesa mucho en ARENA, ya sea porque recurre a él según la conveniencia del momento, ya sea porque lo persigue como un fantasma. No obstante los cambios y las novedades de la transición, ARENA sigue anclada en el pasado, es heredero de sus orígenes guerreros.

Sin la ideología anticomunista y de la guerra fría, ARENA tiene poco que ofrecer como partido. Le faltan ideas y propuestas creativas para resolver los problemas nacionales. Por eso, su plataforma legislativa pasó desapercibida, a 
diferencia de la del FMLN, que sí suscitó interés y discusión al presentar algunas alternativas a las políticas económicas actuales. Reemplazar la dirección actual de ARENA puede ayudar a su renovación, le proporcionarla una nueva imagen de cara a la opinión pública. Pero con toda probabilidad, ello no es suficiente. El partido en cuanto tal reclama una revisión radical que incluya su ideología y organización, lo cual, obviamente, si se llevara a cabo, transformaría su identidad tradicional, una identidad fraguada al calor de la guerra civil. Sin duda, para emprender reformas de este calibre son necesarias mucha audacia y creatividad.

Los cambios que la sociedad y la realidad demandan pasan por el replanteamiento de las relaciones entre la sociedad y el Estado. Más en concreto, la sociedad debe adquirir poder para controlar a los partidos políticos y también a las instituciones estatales. En este sentido, los medios de comunicación de masas pueden desarrollar un papel insustituible para hacer of́r la voz y hacer sentir la presión social sobre la clase política. La sociedad no puede seguir permitiendo que los políticos continúen debilitando la institucionalidad estatal $y$, en particular, aquellas instituciones que nacieron a raíz de los acuerdos de paz. La corrupción y la perversión de la institucionalidad estatal es lo que ha provocado la indiferencia de la población ante la actividad política. Ha llegado el momento, sin embargo, de recuperar esa institucionalidad para ponerla al servicio de los intereses populares y de una democratización verdadera. Tal vez no sea demasiado tarde aún para superar la indiferencia y forzar a la clase política a cumplir su cometido democrático.

La democratización de El Salvador sólo podrá ser real cuando comience a superar las tres contradicciones que la conforman en la actualidad. La primera de estas contradicciones es la de la distribución del ingreso. Mientras el 20 por ciento de la población recibe el 48 por ciento del ingreso nacional, el otro 20 por ciento se tiene que conformar con sólo el 8 por ciento del mismo. La segunda contradicción se da entre quienes se sienten seguros, porque cuentan con la protección que dan el poder y el dinero, los cuales les permiten comprar seguridad ante cualquier posible amenaza, física o judicial, y los que, por no tener ninguna de las dos, viven sumergidos en la inseguridad, sometidos a toda clase de amenazas y peligros. Y, finalmente, la contradicción entre quienes han sido victimas del poder y la impunidad y quienes, por tener poder e impunidad, niegan la verdad, escapan de la justicia y siguen causando victimas.

Es esta realidad política, ahora mucho más evidente que antes, la que debiera llevar a la mesa de negociación a los actores principales de la política y la que los debiera motivar a buscar una concertación desde una perspectiva nacional. Por lo tanto, la concertación no debiera limitarse a los intereses particulares de cada uno de los partidos políticos, sino que estos intereses ni siquiera debieran ocupar el primer lugar en la agenda. Si la concertación no adquiere una dimensión nacional y popular, los partidos podrán resolver sus diferencias e incluso puede que acuerden un entendimiento que les permita convivir civilizadamente en 


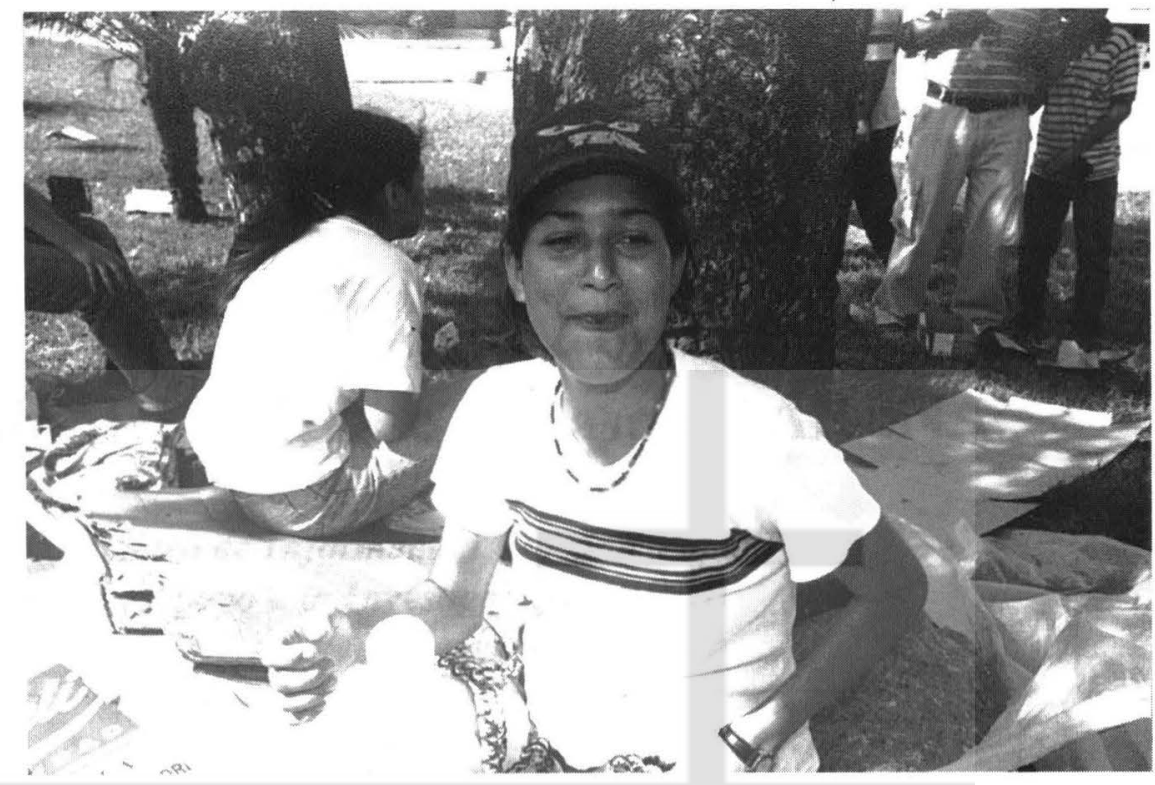

los próximos tres años, pero no contribuirán a la superación de las contradicciones fundamentales que constituyen la realidad nacional.

La concertación debiera desarrollarse desde una perspectiva nacional, debiera orientarse a procurar la satisfacción de las necesidades básicas de la mayor parte de la población salvadoreña y debiera concentrarse en unos pocos temas con los cuales es muy difícil no estar de acuerdo: combatir la corrupción, luchar contra la evasión y elusión fiscal y avanzar hacia una reforma tributaria, garantizar la seguridad ciudadana, explorar con amplitud de miras las alternativas económicas de El Salvador e implementar la reforma del sistema electoral. Sin duda, hay otros temas en la agenda nacional, pero éstos reúnen varias ventajas: permitirían concentrar los esfuerzos en algunos de los problemas más importantes, de tal manera que los progresos que se consiguieran transformarían de manera radical El Salvador actual; en la medida en que se vaya avanzando en la resolución de estos problemas, se abriría espacio para retomar otros que también son urgentes $y$, finalmente, es muy difícil no estar de acuerdo en la relevancia que tales problemas tienen para el futuro de un El Salvador viable y sostenible, más equitativo y vivible.

Ni la amargura de la derrota ni la euforia del triunfo deben hacer olvidar a ARENA y al FMLN que la mayoría de la población salvadoreña en edad de votar no votó por ninguno de ellos. Su mayor desafío consiste, entonces, en demostrarle que gobiernan para ella, que sus intereses son primero, aun antes: que los del partido o que los de ciertos grupos de interés y, o poder, que las elecciones son un instrumento valioso para producir cambios, porque éstos ocurren en realidad.

San Salvador, 24 de marzo de 2000. 